\title{
Usage of Alternate Assessment tool for enhanced understanding of Product Design and Development course at BMSCE
}

\author{
Madhav Murthy \\ Department of Mechanical Engineering, \\ BMS College of Engineering \\ Bangalore,India-560019 \\ madhavnie@gmail.com
}

\begin{abstract}
Product Design and Development is a discipline that is required for engineers of all domains. In simple terms, product design brings in the users(human element) way of making a product. It is proved that, application of product design concepts paves way for successful product development with optimum utilization of resources. Product design is a set of tasks which starts with Product/Problem identification and followed by project planning, concept generation, selection, testing, prototyping, manufacturing the product to be produced.
\end{abstract}

This course is a department elective for the students of seventh semester mechanical engineering. This article focuses on usage of alternate assessment tools for the enhanced understanding of the subject by the student. The students were made to design a questionnaire for the topics assigned to them in the class, which varied from 4 wheeler automobile to smart phone. The intention of using alternate assessment tool was multifold; i) Market exposure for the student ii)Implementation of theory into practice iii)Satisfaction of learning a course iv) Preparedness of using the course in their career.

Keywords- Product design, alternate assessment tool,Enhanced understanding, questionnaire design

\footnotetext{
Madhav Murthy

Department of Mechanical Engineering,

BMS College of Engineering

Bangalore,India-560019

madhavnie@gmail.com
}

\section{Introduction}

Introduction: A product can be understood as a bundle of attributes which is offered to customer for the fulfillment of the needs. Product design is a set of tasks which starts with Product/Problem identification and followed by project planning, concept generation, selection, testing, prototyping, manufacturing the product to be produced as is evident from flow chart. A structured product development process offers several benefits to the firm which is as follows;

i) Better planning and coordination

ii) Improved management and quality assurance

iii) Enhanced morale and satisfaction for customer and employee/employer

The generic product development process consists of six phases namely;

Phase 0: Planning, Phase 1:Concept development Phase 2: System level design, Phase 3: Detail design, Phase 4: Testing and refinement \& Phase 5: Ramp-up Product design is an area which is most essential for engineering professionals across the globe. It helps in making the product, customer friendly.

Flow chart: Overview of Product design process (courtesy: Ulrich, Eppinger " Product Design and Development, McGraw Hill publications)

The current article made use of a new inclusion in the assessment system by BMS board of studies called as "alternate assessment tool (AAT) " which is a component of continuous internal evaluation for 10 marks out of 50 for undergraduate students. It is also an established fact in Indian context that, marks plays 
significant role and hence the seriousness with which the student community looks at such activities will be naturally very committed. The course involves understanding needs of the customer, identifying the market segment, gathering raw data from customer by various methods, generating various concepts for a

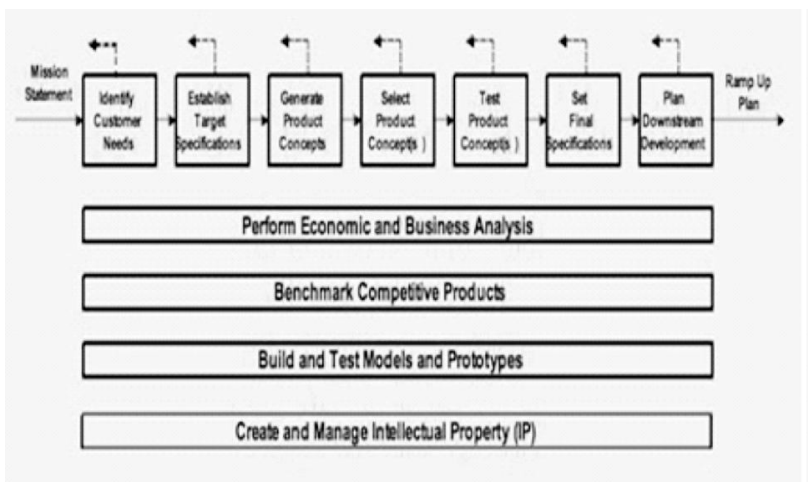

problem before arriving at one solution and so on. The course is a conceptual one where the student will not understand the dynamics of each of the above mentioned activities without getting involved. In this regard, the students were assigned topics by the course instructor which had a mix of various areas. The list of topics on which the students were asked to conduct a field survey by designing a questionnaire is as follows;

a) Air bag deployment system b) safety and storage requirements in a two wheeler c) Mobile phone survey d) Best handling type in 3-4 wheeler load carrier vehicles e) Customer feedback on apple products f) Survey on use of bicycles in Bangalore g) Customer survey on car interiors h) Problems faced by a woman driver i) Survey on bicycle industry j) Survey on higher education abroad k) Central view mirror in auto rickshaw 1) A survey to understand the consumer behavior on preferences in furniture purchasing $\mathrm{m}$ ) A survey to understand the consumer behavior on mobile phone purchasing preferences n) Interior Design And Ergonomics etc to name a few.

\section{Implementation of Aat}

The students were asked to conduct a market survey by designing a questionnaire, record the data effectively, translate it in the form of a report and present it before the panel for assessment. There was continuous guidance by the course instructor regarding the work assigned.
Although this method of assessing consumes more time than the traditional approach of conducting quiz, it is worth taking that extra effort as it makes more justification for the teaching learning process. This method is far more reaching than the approach used more commonly.

Let us consider one of the topics and understand the effectiveness of the AAT towards enhanced learning. The set of questions for survey as designed by one of the student on the topic Interior Design and Ergonomics is given below:

1. On a scale of 1 to 10 , with 1 being the least and 10 being highest, how would you rate the interiors of the car?

2. Do you think the cost is justified with the design and ergonomics of the interiors provided? yes no .

3. On a scale of 1 to 10 , with 1 being the least and 10 being highest, how would you rate the infotainmant system of the car.

4. Which feature in your car infotainment system according to you is the best.

5. Addition of which feature in the infotainment system do you think improve driving of the system.

6. Does your car have a climate control system? yes no

7. Does your car have steering mounted audio controls? yes no

8. Does your car have rake and reach adjustable steering wheel? yes no

9. Does your car have rear parking sensors? yes no

10. Are you satisfied with the storage space available in yourcar? yes no

11. Are you satisfied with the seating posture of the car? yes no .

If no, why?

12. Is your car equipped with central arm rest? yes no

13. Out of the above features, what features do you think will greatly improve your driving experience?

Thank you very much for your co-operation.

*This information will be used for college purposes

only and will not be disclosed with anyone.

The students were educated about questionnaire 
design in the class by the course instructor after which they started implementing it for the survey work. All the students had great interests in carrying out such an assignment as this approach was something new. It made them to meet customers at various places from colleges to traffic signals, showrooms to parks and understand the dynamics involved, data collection and compilation. Once the survey was conducted, they used their own methods to represent the data and their analysis of the work which was worth appreciating. They presented the work before their course instructor and it was assessed for 10 marks considering all the efforts made by the student.The methods that they used to represent the data were Bar graphs, pie charts, videos, ratios etc.

\section{Outcomes of Aat}

The intention with which such an activity being assigned to students was that, students should implement the theory in real world atleast to a small extent. The end result of such an activity was very encouraging as students presented seminars in a very meticulous way (although the marks for assessment were only 10 marks). This also showed that marks play a vital role for a student in terms of his interest/commitment.

The outcomes of the survey are; two of the surveys will be published in a national conference and one survey will be published in an international journal. Two of the students are working in the area of product development and the learning that were a part of at BMSCE is helping them in their workplace.

\section{Conclusion}

The AAT has made a great impact for the understanding of the subject for the students, which motivates me to use AAT for every subject that I teach. I also recommend it to other faculty members to customize AAT as applicable to their course. It is also noticeable that the AAT was taken well by student fraternity and was effective in enhanced understanding of the topics in the course

\section{Acknowledgment}

Sincere thanks to the management of BMS. Thanksto our beloved Principal and H.O.D Mechanical engineering for bringing in such initiatives and supporting.

\section{References}

[1] Ulrich \& Eppinger Product Design and Development, McGraw Hill publications

[2] Product Design and Manufacturing A.K. Chitale, R. C. Gupta,PHI Learning Pvt. Ltd., 2005

[3] Questionnaire design, interviewing and attitude measurement- A.N Oppenheim, Bloomsbury Academic, 1992 